\title{
A Study of the Postmodernistic Characteristics in The Catcher in the Rye
}

\author{
Gu Jia \\ Henan Industrial and Trade Vocational College, Zhengzhou, People R China \\ 191760548@qq.com
}

Key Words: the Catcher in the Rye, postmodernistic characteristics,vulgar language, the anti-hero; alienation theme

\begin{abstract}
The Catcher in the Rye, written by Jerome David Salinger, has been a controversial novel on its classification.So far as now, the literature world has reached a consensus that it is a growing-up novel and embodies the theme of "the quest" which inherits from the western literature tradition. While apart from the theme of "quest", there are also many apparent and significant features which cannot be ignored in evaluating its classification of "postmodernity".This paper is going to reveal the postmodernistic characteristics based on three aspects: the vulgar language, the anti-hero, and alienation theme.
\end{abstract}

\section{Introduction}

The Catcher in the Rye is a 1951 novel by Jermo David Salinger. Originally published for adults, it has now become popular with adolescent readers for its themes of teenage angst and alienation(Costello and Harold, 2010). It has been translated into almost all of the world's major languages. About 250,000 copies are sold each year with total sales of more than 65 million books. The novel's protagonist Holden Caulfield has become an icon forteenage rebellion.The novel also handles complicated issues of identity, belonging, loss, and connection.

The author, Jerome David Salinger(1919- ), one of the most popular and influential authors of American writers after World War II, is best known for the controversial novel The Catcher in the Rye(1951), which has now become one of the two "modern classics" in contemporary American literature (the other one is Ralph Ellison's The Invisible Man published in 1952). When this novel was first published, the critics held totally different views: some praised it as a significant success while others panned it as a disappointing failure. Rohrer writes, "Many of these readers are disappointed that the novel fails to meet the expectations generated by the mystique it is shrouded in. J. D. Salinger has done his part to enhance this mystique. That is to say, he has done nothing."(Rohrer,2009) Rohrer assessed the reasons behind both the popularity and criticism of the book, saying that it "captures existential teenage angst" and has a "complex central character" and "accessible conversational style". While at the same time some readers may dislike the "use of 1940s New York vernacular" and call the book’s vulgar and obscene language. Morris Longstreth, writing for Christian Science Monitor, even commented The Catcher in the Rye as a book "not fit for children to read" (7).

Then after the book has gained fair and objective evaluations it deserves from literature reviewers, the controversy is no longer confined to the book's significance itself, but goes to the debate on what kind of novel it belongs to. So far as now, the literature world has reached a consensus that The Catcher in the Rye is a growing-up novel, for like other growing-up novels such as The Adventures of Huckberry Finn, this novel embodies the theme of "the quest" which inherits from the western literature tradition. It's true that such an agreement is necessary for the convenience of literary criticism in literary classification, but apart from the theme of "quest", there are also many apparent and significant features which can never be ignored in evaluating its classification, such as the peculiar language and narrative, the characterization of an anti-hero which is totally against tradition, alienation and fragmentation which permeats in the narration of the novel. All these have shown evidence of this book's postmodernity. Through an analysis on the 
above three aspects: the vulgar language, the anti-hero, and alienation theme, this paper is going to reveal the postmodernistic characteristics in The Catcher in the Rye.

\section{Brief Illustration on Postmodernism}

In order to find out the postmodernistic characteristics, it is necessary to give a brief illustration on postmodernism first. Conceived in 1910s, postmodernism has been a major literary trend in the western countries in the mid $20^{\text {th }}$ century. Postmodernism could be seen as a result of the failure of modernism which claims it would promote human progress and welfare but indeed coincides with two devastating world wars in which human's cruety has been exerted to its extreme and then people begin to seek an alternative to modernism, which becomes the objective reason for the prosperity of postmodernism. According to Fredric Jameson, the most famous theorist on postmodernism in US, a very useful word invented by Sartre can be used for describing postmodernism: derealization. Like wax statues which have nothing inside though from the appearance they have nothing different from real human being, postmodernism is the same thing in this perspective, in which everything could be derealized, and can become something like wax statues. Jameson furtherly argues that in postmodernist society people would feel rootless and being floating on the surface. What's more, Jameson points out an illness of "fragmentation" in postmodernism, a state in which one has no whole self and no self-identity or other identities. Postmodernism works' rebellious spirit against the traditional literary works often lies in its disthronement for the central status of mainstream culture and blurring the distinction between noble culture and popular culture. This disthronement and blurring first and foremost apparently find its way in the language of The Catcher in the Rye.

\section{Postmoderistic Characteristics of The Catcher in the Rye}

Characterized by abundant use of colloquial language and slangs, loose structure, and vulgar and obscene expressions, this novel has now become a historial linguistic record of a type of American speech popular among high school students around 1950s. American critics Donald P. Costello concludes in his essay that:

The language of The Catcher in the Rye is, as we have seen, an authentic artistic rendering of a type of informal, colloquial, teenage American spoken speech. It is strongly typical and trite, yet often somewhat individual; it is crude and slangy and impressive, imitative yet occasionally imaginative, and affected toward standardization by the strong efforts of schools. (45)

1) "Old" - term of familiarity or endearment.

2) "Phony" - superficially acting a certain way only to change what others think of you

3) "That killed me" - I found that hilarious or astonishing

4) "Flit" - homosexual

5) "Crumbum" or "crumby"- inadequate, insufficient, disappointing

6) "Snowing" - sweet-talking

7) "I got a bang out of that" - I found it hilarious or exciting

8) "Shoot the bull" - have a conversation containing false elements

9) "Give her the time" - sexual intercourse

10 "Chew the fat" or "chew the rag" - small-talk

11) "Rubbering" or "rubbernecks" - idle onlooking/onlookers

12) "The Can" - the bathroom

From the aspect of syntactics, the loose structure is Holden's most outstanding style of speech. This loose structure is born out by the fragments, after-thoughts, abbreviations, and syntactic repetition of certain words and sentences, which can be seen from the following examples: 
1) Fragment: Now he's out in Hollywood, D.B., being a prostitute. (Salinger 5)

2) After-thought: It has a very good academic rating, Pencey. (7)

3) Abbreviations:Willya - will you ,

Whuddaya - what do you

Helluva - hell of you

4) Repetition of certain words:

They are nice and all...(5)

I'm not going to tell you my whole goddam autobiography or anything.(5)

....and he is my brother and all. (5)

Anyway, it was December and all. (8)

Salinger's use of vulgar language breaks the traditional notion about art which believes art is permanently noble and beyond the earthly life. The modernists treats art as a field independant from realistic world, while Salinger blurs the distinction between the ideal and the realstic and fills the gap between the elite culture and mass culture.

Anti-hero, as one of the main postmodernistic characteristics, is another prominent feature in The Catcher in the Rye. Holden is an anti-hero against literature tradition as well as mainstream culture. Merriam-Webster's Collegiate Dictionary 11th Edition (1714) defines anti-hero as "a protagonist or notable figure who is conspicuously lacking in heroic qualities.” Holden is such a figure: he is not possessed with such heroic qualities as courageousness, powerfulness and so on but opposed to school, adults, and the whole society. Careful readers may not fail to notice that one word Holden utterly detests is "phony", which appears in Holden's speech for nearly 50 times. In Holden's judgment, Pencey Prep, as well as any other schools, is only home for phoniness, dishonesty, and deceiving. However, outside of school, things are even worse. In his three-day wandering in New York City, the phoniness and obscenity encountered by him makes him more depressed. He learns that the routine life of people---adults, and people around his age---is talking about movies and movie stars, going to shows, lingering in clubs, trying sexual intercourse without girls, drinking alcohol, dancing, skating, or just doing nothing. Holden is opposed to all those old routines and stick to his own opinions, even about literature. He thinks that Out of America is a good book while in contrast, A Farewell to Arms has become a real phony book to him. Like Yossarian, the protagnist of Cathch-22, who spares no effort in escaping the fly on the battlefield and satirizes the hypocracy and cruelty of war, Holden is also an anti-hero who rebels against the phoniness of the society.

Besides that, the theme of alienation, which makes its frequent appearance in postmodernistic works also finds its way in The Catcher in the Rye. Throughout the novel, Holden seems to be excluded from and victimized by the world around him. As he says, he feels trapped on "the other side” (18) of life, and he continually attempts to find his way in a world which he feels he doesn't belong to. The opening scene of the novel reveals Holden's alienation from a society to which he is expected to adapt and adjust. He begins telling his story literally isolated in an isolated psychiatric hospital. Misunderstanding happens all the time and Holden is alienated from the school, his parents, his surroundings and even well-intentioned people like Spencer.

Spencer is one among many with whom Holden is unable to communicate effectively. Attempting to tell his history teacher about his failure at Pencey, Holden acknowledges that he cannot communicate with him, "He wasn't listening. He hardly ever listened to you when you said something" (14). He believes Spencer wants to help, but communication is impossible because "it was just that we were too much on opposite sides of the pole, that's all” (19). During their communication, Mr. Spencer tries to toss the magazine on the bed, but he misses, and Holden picks up the magazine. "The magazine, which falls to the floor, is meant, perhaps, to represent adult knowledge and experience; the 'toss-and-miss' game demonstrates the lack of connection between the world of the adult and the adolescent" (Alexaneder 14). Alienation also exists in Holden and his parents. In his movie fantasy of pulling the peak of the hunting cap over his eyes and showing about being blind, Holders shouts, "Mother darling, everything's getting so dark in here," and "Mother darling, give me your hand. Why won't you give me your hand (26)?” This seems like clowning, but in fact it is a manifestation of his terrible anguished isolation from his family. He tells Spencer 
that he intends for seeing his parents next week, but he has not "communicated with them" (12). Therefore Holden is also alienated from his parents.

\section{Conclusion}

As postmodernism is not divided from modernism by an iron wall, a writer may sometimes bring out a piece both of modernism and postmodernism without consciousness of putting it into which classification (Joyce's Finnegan's Wake and Faulkner's The Sound and Fury are good examples). This paper, through the analysis above related to the language traits, the anti-hero characterization, the alienation in this novel, reveals that The Catcher in the Rye is a classic of growing-up novel with some apparent post-modernistic characteristics, though it is not as postmodernistic as those novels such as Pale Fire by Voladimir Nabokov, or As I Lay Dying by William Faulkner. The prominent characteristics, such as fragmentation and alienation, the discontinuity of language, the anti-traditional characterization and the mental disorder which are the features of a postmodernistic work and also appear in this novel, can never be ignored.

\section{References}

[1] Alexaneder, Charlotte A. J. D. Salinger's The Catcher in the Rye. Beijing: Foreign Language Teaching\&Research Press, 1997.

[2] “Anti-hero.” Merriam-Webster's Collegiate Dictionary $11^{\text {th }}$ ed. 1714

[3] Costello, Donald P. “The Language of The Catcher in the Rye” American Speech 34 (1959): 45-53

[4]Costello, Donald P., and Harold Bloom. "The Language of "The Catcher in the Rye.." Bloom's Modern Critical Interpretations: The Catcher in the Rye (2000): 11-20. Literary Reference Center. EBSCO. Web. Dec 1, 2010.

[5] Jameson, Fredric. Postmodernism and Theories of Culture. Beijing: Peking University Press, 1997.

[6] Longstreth, Morris. "Review of The Catcher in the Rye" Christian Science Monitor 19 July 1951: 7.

[7] Rohrer, Finlo (June 5, 2009). "The why of the Rye". BBC News Magazine (BBC). Retrieved 2009-06-05.

[8]Salinger, J.D._The Catcher in the Rye. New York: Penguin Books Inc. 1958. 